\title{
Reduced Dose Intensities of Doxorubicin in Elderly Patients with DLBCL in Rituximab Era
}

\author{
Hyerim $\mathrm{Ha}, \mathrm{MD}^{1}$ \\ Bhumsuk Keam, MD, PhD ${ }^{1,2}$ \\ Tae Min Kim, MD, PhD',2 \\ Yoon Kyung Jeon, $\mathrm{MD}, \mathrm{PhD}^{3}$ \\ Se-Hoon Lee, MD, PhD ${ }^{1,2}$ \\ Dong-Wan Kim, MD, PhD ${ }^{12}$ \\ Chul Woo Kim, MD, PhD ${ }^{3}$ \\ Dae Seog Heo, MD, PhD ${ }^{1,2}$
}

\begin{abstract}
Purpose
The dose intensity of doxorubicin (DID) is important to the survival of diffuse large B cell lymphoma (DLBCL) patients. However, due to expected toxicities, most elderly patients cannot receive full doses of anthracyclines. The purpose of this study was to evaluate the effect of DID on the survival of elderly DLBCL patients (age $\geq 70$ years) in the rituximab era.
\end{abstract}

\section{Materials and Methods}

We analyzed 433 DLBCL patients who were treated with R-CHOP between December 2003 and October 2011 at the Seoul National University Hospital. Of these patients, 19.2\% were aged $\geq 70$ years. We analyzed the survival outcomes according to DID.

\section{Results}

Significantly poorer overall survival (OS) was observed for patients aged $\geq 70$ years (2-year OS rate: $59.9 \%$ vs. $84.2 \% ; p<0.001$ ). DID $\leq 10 \mathrm{mg} / \mathrm{m}^{2} /$ wk had a significant effect on the OS and progression-free survival (PFS) in elderly patients (2-year OS rate: $40.0 \%$ in DID $\leq 10 \mathrm{mg} / \mathrm{m}^{2} /$ wk vs. $62.6 \%$ in DID > $10 \mathrm{mg} / \mathrm{m}^{2} /$ wk; $p=0.031 ; 2$-year PFS: $35.0 \%$ vs. $65.7 \%$; $\mathrm{p}=0.036$ ). The OS on each $1.7 \mathrm{mg} / \mathrm{m}^{2} /$ wk doxorubicin increment above $10 \mathrm{mg} / \mathrm{m}^{2} /$ wk in elderly patients was not significant among the groups (2-year OS rate: $75.0 \%$ in DID 10.0$11.7 \mathrm{mg} / \mathrm{m}^{2} / \mathrm{wk}$ vs. $66.7 \%$ in DID $15.0-16.7 \mathrm{mg} / \mathrm{m}^{2} / \mathrm{wk} ; \mathrm{p}=0.859$ ). Treatment related mortality was not related to DID.

\section{Conclusion}

DID can be reduced up to $10 \mathrm{mg} / \mathrm{m}^{2} /$ wk in elderly DLBCL patients in the rituximab era. Maintenance of DID $>10 \mathrm{mg} / \mathrm{m}^{2} / \mathrm{wk}$ and judicious selection of elderly patients who are tolerant to DID is necessary.
Correspondence: Bhumsuk Keam, MD, PhD Department of Internal Medicine,

Seoul National University Hospital,

101 Daehak-ro, Jongno-gu, Seoul 03080, Korea

Tel: 82-2-2072-7215

Fax: 82-2-2072-7379

E-mail: bhumsuk@snu.ac.kr

Received December 2, 2014

Accepted March 11, 2015

Published Online April 9, 2015
Key words

Diffuse large B-cell lymphoma, Age groups, Doxorubicin

\section{Introduction}

The incidence of diffuse large B cell lymphoma (DLBCL) increases with age, with approximately $40 \%$ of patients aged over 70 years [1]. Further increased incidence of DLBCL is projected since life expectancy has grown worldwide. Combination chemotherapy has improved the prognosis of DLBCL; before the rituximab era the standard treatment included cyclophosphamide, doxorubicin, vincristine, and prednisolone (CHOP) [2]. While CHOP has improved the treatment outcome, many studies have shown that elderly patients with DLBCL had a low survival rate because of poor performance status, comorbidity or reduced dose of doxorubicin $[3,4]$. Whether DLBCL in elderly patients is associated with a specific genetic abnormality or histologic characteristic is not yet clear [5]. Elderly patients have a decreased ability to tolerate treatment and are more vulnerable to the toxic effects of chemotherapy such as doxorubicin than younger DLBCL patients. Dose reduction of doxorubicin may lead to 
Table 1. Characteristics of DLBCL patients treated with R-CHOP

\begin{tabular}{|c|c|c|c|c|}
\hline Characteristic & No. of patients (\%) & Age $<70 \mathrm{yr}$ & Age $\geq 70 \mathrm{yr}$ & p-value \\
\hline \multicolumn{5}{|l|}{ Age } \\
\hline No. $(\%)$ & 433 & $350(80.8)$ & $83(19.2)$ & \\
\hline Median (range) & $58(16-91)$ & $54(16-69)$ & $74(70-90)$ & \\
\hline \multicolumn{5}{|l|}{ B Symptoms } \\
\hline No & $327(75.5)$ & $265(75.7)$ & $62(74.7)$ & 0.847 \\
\hline Yes & $106(24.5)$ & $85(24.4)$ & $21(25.3)$ & \\
\hline \multicolumn{5}{|l|}{ Ann Arbor stage } \\
\hline I/II & $233(53.8)$ & $192(54.9)$ & $41(49.4)$ & 0.370 \\
\hline III /IV & $200(46.2)$ & $158(45.1)$ & $42(50.6)$ & \\
\hline \multicolumn{5}{|l|}{ Performance status } \\
\hline ECOG 0-1 & $357(82.4)$ & $303(86.6)$ & $54(65.1)$ & $<0.001$ \\
\hline ECOG 2 or more & $76(17.6)$ & $47(13.4)$ & $29(34.9)$ & \\
\hline \multicolumn{5}{|l|}{ LDH level } \\
\hline Normal & $179(41.3)$ & $148(42.5)$ & $31(37.3)$ & 0.390 \\
\hline Elevated & $252(58.2)$ & $200(57.5)$ & $52(62.7)$ & \\
\hline \multicolumn{5}{|c|}{ No. of extranodal sites } \\
\hline $0-1$ & $222(51.3)$ & $181(51.7)$ & $41(49.4)$ & 0.704 \\
\hline 2 or more & $211(48.7)$ & $169(48.3)$ & $42(50.6)$ & \\
\hline \multicolumn{5}{|l|}{ IPI score } \\
\hline $0-1$ & $208(48.0)$ & $184(52.6)$ & $24(28.9)$ & $<0.001$ \\
\hline 2 & $105(24.2)$ & $83(23.7)$ & $22(26.5)$ & \\
\hline 3 & $71(16.4)$ & $53(15.1)$ & $18(21.7)$ & \\
\hline $4-5$ & 49 (11.3) & $30(8.6)$ & $19(22.9)$ & \\
\hline \multicolumn{5}{|c|}{ Bone marrow involvement } \\
\hline Absence & $355(82.0)$ & $295(86.0)$ & $60(76.9)$ & 0.046 \\
\hline Presence & $66(15.2)$ & $48(14.0)$ & $18(23.1)$ & \\
\hline \multicolumn{5}{|l|}{ Bulky disease } \\
\hline No & $340(78.5)$ & $274(78.3)$ & $66(79.5)$ & 0.806 \\
\hline Yes & $93(21.5)$ & $76(21.8)$ & $17(20.5)$ & \\
\hline
\end{tabular}

DLBCL, diffuse large B cell lymphoma; R-CHOP, rituximab plus cyclophosphamide, doxorubicin, vincristine, and prednisone; ECOG, Eastern Cooperative Oncology Group; LDH, lactate dehydrogenase; IPI, International Prognostic Index.

different survival rates between young and old patients [6,7].

Rituximab, a chimeric monoclonal antibody against the CD20 protein has demonstrable efficacy in DLBCL patients $[8,9]$. Rituximab combination therapy has dramatically increased treatment outcomes. Several studies have indicated that the addition of rituximab to CHOP (R-CHOP) increased cure rates by $10 \%-15 \%$ in elderly patients, hence R-CHOP has become the new standard treatment $[8,10]$. Dose intensity of doxorubicin (DID) was important before the rituximab era [6,11]; however, few studies on proper DID are found in the literature.

To the best of our knowledge, few studies analyzing the effect of doxorubicin dose on treatment outcomes in elderly DLBCL patients in the rituximab era have been reported. The purpose of this study was to analyze the treatment outcomes of elderly patients who were treated with R-CHOP according to the DID.

\section{Materials and Methods}

\section{Patients and treatment}

We conducted a single center retrospective analysis of DLBCL patients treated with R-CHOP at the Seoul National University Hospital between December 2003 and October 2011. Inclusion criteria were (1) pathologically confirmed DLBCL patients according to World Health Organization criteria by specialized hematopathologists (Y.K.J. and C.W.K.) [12]; (2) patients who received first-line therapy with RCHOP. Full dose R-CHOP consisted of $375 \mathrm{mg} / \mathrm{m}^{2}$ rituximab, $750 \mathrm{mg} / \mathrm{m}^{2}$ cyclophosphamide, $50 \mathrm{mg} / \mathrm{m}^{2}$ doxorubicin and $1.4 \mathrm{mg} / \mathrm{m}^{2}$ vincristine on day 1 , and $100 \mathrm{mg}$ oral prednisolone on days 1-5 of each cycle. The combination treatment was repeated at 3 -week intervals. Patients who 


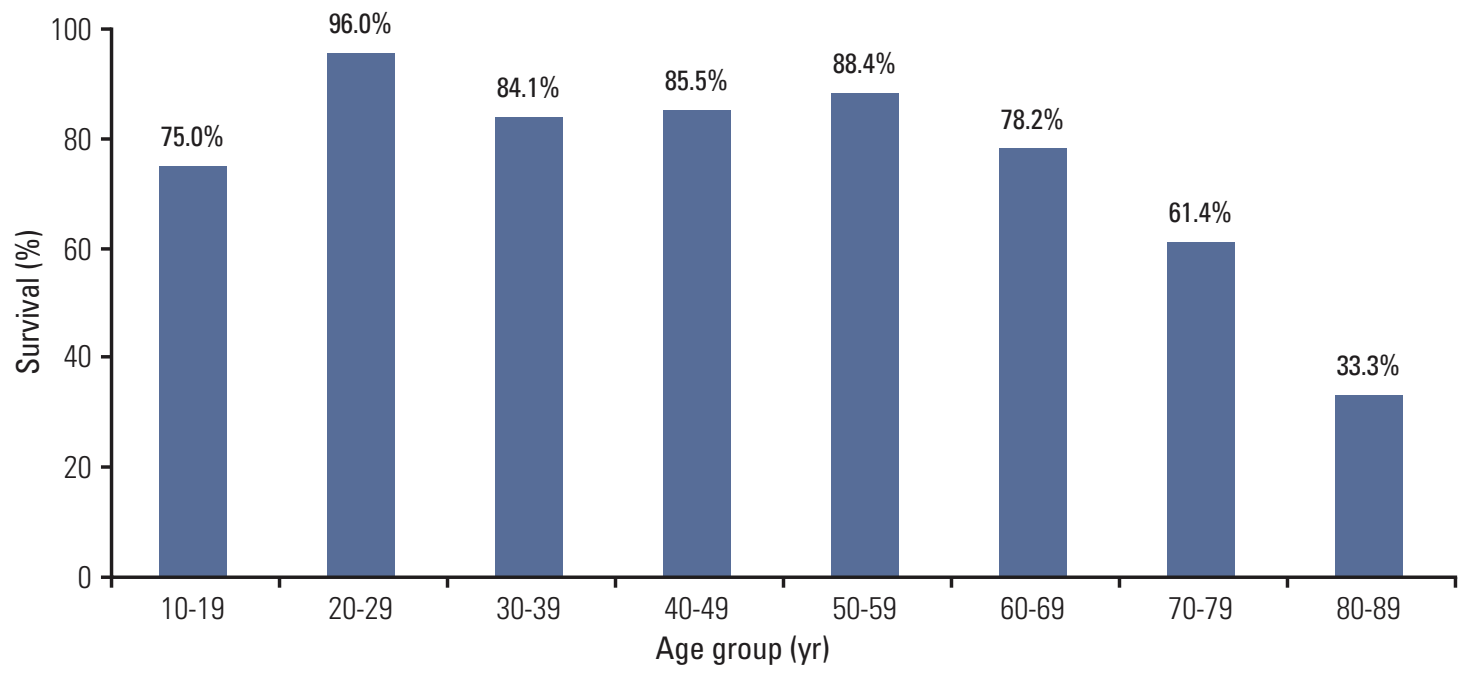

Fig. 1. Age-specific 2-year overall survival rate.

Table 2. Number and survival outcomes of patients from each subgroup according to DID in elderly DLBCL patients (age $\geq 70$ years)

\begin{tabular}{|c|c|c|c|c|}
\hline \multirow[t]{2}{*}{ DID (mg/m²/wk) } & \multicolumn{2}{|c|}{$\begin{array}{l}\text { No. of patients in each } \\
\text { subgroup (\%) }\end{array}$} & \multicolumn{2}{|c|}{$\begin{array}{l}\text { 2-Year PFS/OS rate (\%) } \\
\text { according to DID subgroup in aged } \geq 70 y\end{array}$} \\
\hline & Age $<70 \mathrm{yr}$ & Age $\geq 70 \mathrm{yr}$ & 2-Year PFS rate & 2-Year OS rate \\
\hline (a) $6.7<\mathrm{DID} \leq 8.3$ & $5(1.4)$ & $5(6.0)$ & 30.0 & 20.0 \\
\hline (b) $8.3<\mathrm{DID} \leq 10.0$ & $3(0.9)$ & $5(6.0)$ & 40.0 & 60.0 \\
\hline (c) $10.0<$ DID $\leq 11.7$ & $6(1.7)$ & $8(9.6)$ & 85.7 & 75.0 \\
\hline (d) $11.7<$ DID $\leq 13.4$ & $33(9.5)$ & $35(42.2)$ & 61.1 & 50.4 \\
\hline (e) $13.4<$ DID $\leq 15.0$ & $36(10.3)$ & $9(10.8)$ & 66.7 & 88.9 \\
\hline (f) $15.0<$ DID $\leq 16.7$ & $266(76.2)$ & $21(25.3)$ & 63.8 & 66.7 \\
\hline
\end{tabular}

p-value for 2-year PFS rate: (a+b) vs. ( $c+d+e+f)=0.036$; (a) vs. (b) $=0.271$; (c) vs. (d) $=0.362$; (c) vs. (e) $=0.462$; (c) vs. (f) $=0.392$; (d) vs. $(\mathrm{e})=0.782$; (d) vs. $(\mathrm{f})=0.913$; (e) vs. $(\mathrm{f})=0.815$. $\mathrm{p}$-value for 2 -year $O S$ rate: $(\mathrm{a}+\mathrm{b})$ vs. $(\mathrm{c}+\mathrm{d}+\mathrm{e}+\mathrm{f})=0.031 ;(\mathrm{a})$ vs. (b) $=0.174 ;(\mathrm{c})$ vs. (d) $=0.216$; (c) vs. (e) $=0.577$; (c) vs. (f) $=0.859$; (d) vs. (e) $=0.065$; (d) vs. (f) $=0.103$; (e) vs. (f) $=0.637$. DID, dose intensity of doxorubicin; DLBCL, diffuse large B cell lymphoma; PFS, progression-free survival; OS, overall survival.

received radiotherapy, surgery, and chemotherapy other than R-CHOP were excluded. We analyzed 433 DLBCL patients who initially received R-CHOP. Patients aged $\geq 70$ years were regarded as elderly. Response was assessed on the basis of the modified International Workshop criteria [13].

\section{Measurement of dose intensity}

The dose intensity of the agent was calculated by dividing the total received dose by the number of weeks of treatment $[7,14]$. The patients were stratified according to age and DID. The standard DID was $16.7 \mathrm{mg} / \mathrm{m}^{2} / \mathrm{wk}$. All study patients received over $6.7 \mathrm{mg} / \mathrm{m}^{2} / \mathrm{wk}$ of doxorubicin (40\% dose reduction from standard dose).

\section{Statistical analysis}

The chi-square test was used to compare the percentage between two groups by age or DID. Survival analysis was performed using the Kaplan-Meier method and tested using the log-rank test. Overall survival (OS) was defined as the time from diagnosis until death or the last follow-up. Progression-free survival (PFS) was defined as the time from first day of treatment until disease progression. We used multivariate Cox regression analysis to evaluate prognostic 
Table 3. Treatment outcomes according to the dose intensity

\begin{tabular}{|c|c|c|c|c|c|c|}
\hline \multirow{3}{*}{ Clinical outcome } & \multicolumn{6}{|c|}{ Dose intensity of doxorubicin ( $\left.\mathrm{mg} / \mathrm{m}^{2} / \mathrm{wk}\right)$} \\
\hline & \multicolumn{3}{|c|}{ Age $<70 \mathrm{yr}$} & \multicolumn{3}{|c|}{ Age $\geq 70 \mathrm{yr}$} \\
\hline & $\leq 10$ & $>10$ & p-value & $\leq 10$ & $>10$ & p-value \\
\hline \multicolumn{7}{|l|}{ Attainment of CR } \\
\hline No & $4(44.4)$ & $59(17.3)$ & 0.059 & $4(40.0)$ & $26(35.6)$ & 1.000 \\
\hline Yes & $5(55.6)$ & $282(82.7)$ & & $6(60.0)$ & $47(64.4)$ & \\
\hline \multicolumn{7}{|l|}{ Disease progression } \\
\hline No & $3(33.3)$ & $268(78.6)$ & 0.005 & $4(40.0)$ & $48(65.8)$ & 0.164 \\
\hline Yes & $6(66.7)$ & $73(21.4)$ & & $6(60.0)$ & $25(34.2)$ & \\
\hline \multicolumn{7}{|l|}{ Death } \\
\hline No & $4(44.4)$ & $272(79.8)$ & 0.023 & $2(20.0)$ & $35(47.9)$ & 0.173 \\
\hline Yes & $5(55.6)$ & $69(20.2)$ & & $8(80.0)$ & $38(52.1)$ & \\
\hline 2-Year PFS rate $(\%)$ & 55.6 & 82.0 & $<0.001$ & 35.0 & 65.7 & 0.036 \\
\hline HR for PFS $(95 \% \mathrm{CI})$ & \multicolumn{2}{|c|}{$4.043(1.756-9.305)$} & 0.001 & \multicolumn{2}{|c|}{$2.520(1.021-6.224)$} & 0.045 \\
\hline 2-Year OS rate $(\%)$ & 66.7 & 84.7 & 0.004 & 40.0 & 62.6 & 0.031 \\
\hline HR for OS $(95 \% \mathrm{CI})$ & \multicolumn{2}{|c|}{$3.459(1.394-8.579)$} & 0.007 & \multicolumn{2}{|c|}{$2.242(1.036-4.854)$} & 0.040 \\
\hline
\end{tabular}

Values are presented as number $(\%)$ unless otherwise indicated. CR, complete remission; PFS, progression-free survival; HR, hazard ratio; CI, confidence interval; OS, overall survival.
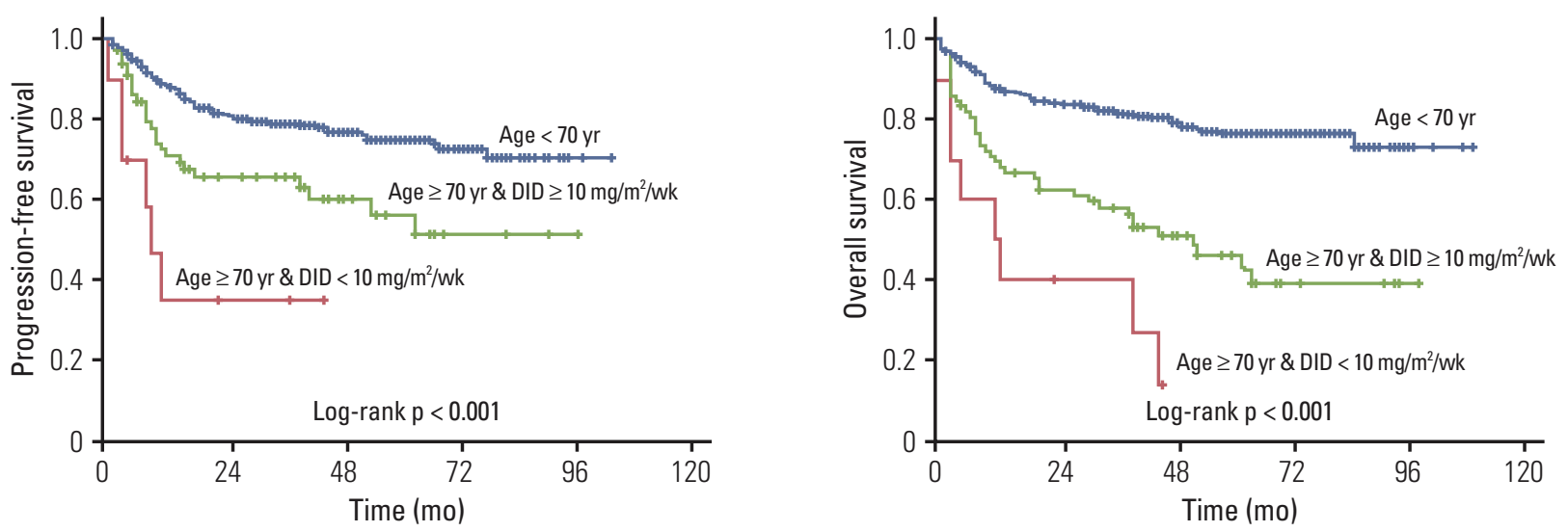

Fig. 2. Kaplan-Meier plots of progression-free survival (A) and overall survival (B) of young patients, elderly patients with dose intensity of doxorubicin (DID) $\leq 10 \mathrm{mg} / \mathrm{m}^{2} / \mathrm{wk}$, and elderly patients with DID $>10 \mathrm{mg} / \mathrm{m}^{2} / \mathrm{wk}$.

factors affecting survival. p-value of $\leq 0.05$ was considered as difference. The study protocol was approved by the Institutional Review Board (IRB) of the Seoul National University Hospital (IRB No. H1-406-001-583). The study was conducted in accordance with the Declaration of Helsinki.

\section{Results}

\section{Patient characteristics}

Of the 433 patients, $83(19.2 \%)$ were aged $\geq 70$ years and $350(80.8 \%)$ were younger than 70 years. The clinical features are shown in Table 1 . There were no significant differences 
A
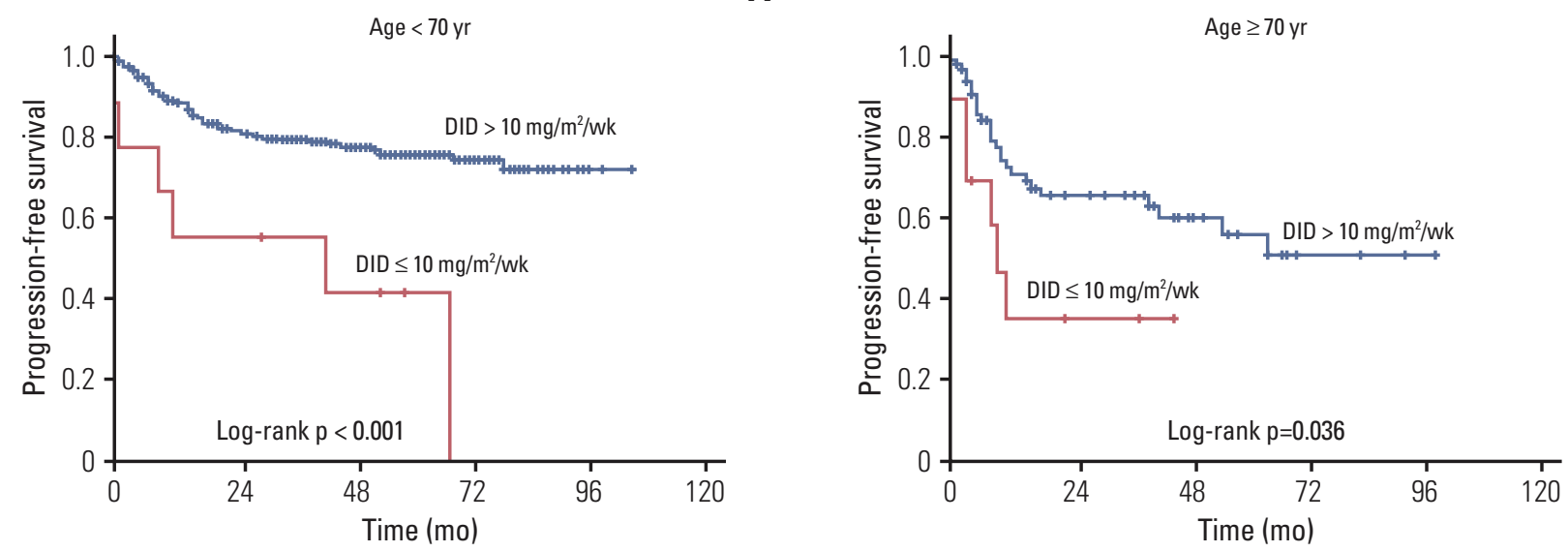

Fig. 3. (A, B) Kaplan-Meier plots of progression-free survival by age and dose intensity of doxorubicin (DID).

A
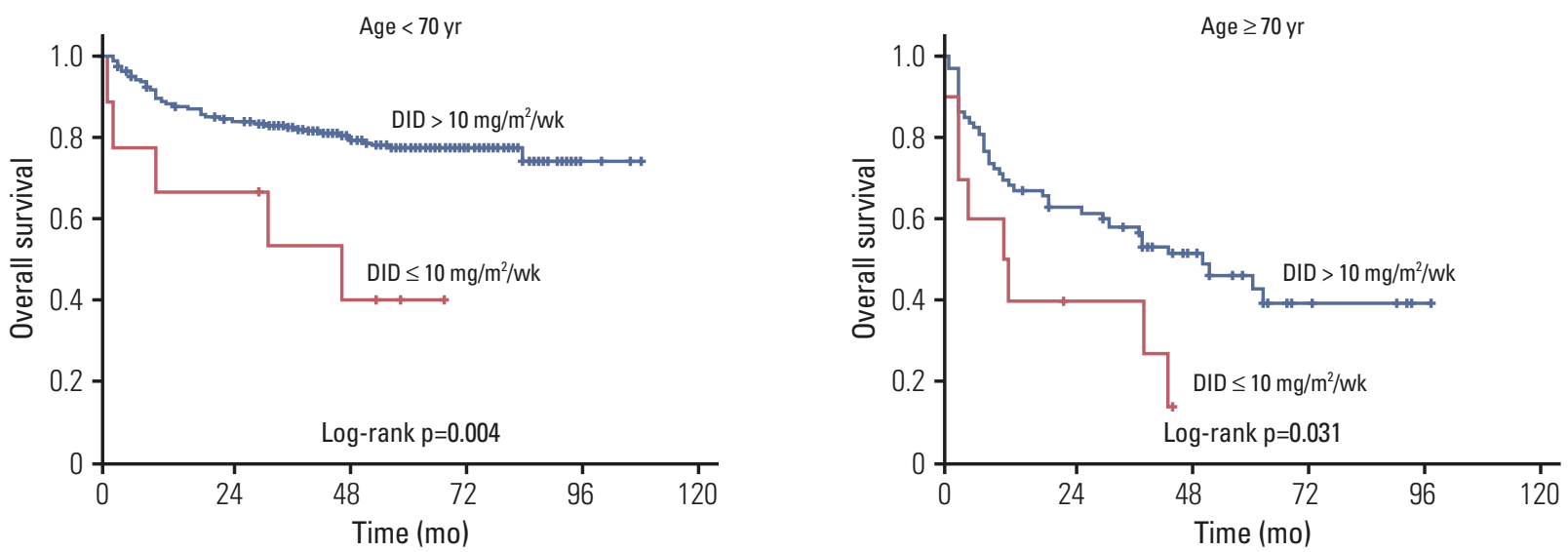

Fig. 4. (A, B) Kaplan-Meier plots of overall survival according to age and dose intensity of doxorubicin (DID).

between the two groups, except for performance status (Eastern Cooperative Oncology Group [ECOG] 0-1 vs. ECOG 2 or more), International Prognostic Index (IPI), and bone marrow involvement.

\section{OS by age group}

OS of the patients with DLBCL who received R-CHOP was analyzed according to age group. Age-specific 2-year OS rate was decreased with age in patients aged $\geq 70$ years, below $70 \%$ (Fig. 1).

\section{Treatment outcomes by DID}

Approximately 53\% of elderly patients received doxorubicin at $11.7 \mathrm{mg} / \mathrm{m}^{2} / \mathrm{wk}<\mathrm{DID} \leq 15.0 \mathrm{mg} / \mathrm{m}^{2} / \mathrm{wk}$ (Table 2). Twenty-four patients (aged $\geq 70$ ) used prophylactic granulocyte-colony stimulating factors, $87.5 \%$ of them received DID $\geq 10 \mathrm{mg} / \mathrm{m}^{2} / \mathrm{wk}$. We analyzed treatment outcomes according to DID in the two age groups as shown in Table 3 and Fig. 2. DID did not have an effect on complete remission (CR) rate, disease progression and death rate in patients aged $\geq 70$ years, however significant differences were observed in the younger than 70 year age group. Two-year PFS and OS showed significant difference according to doxorubicin dose intensity (DID $\leq 10 \mathrm{mg} / \mathrm{m}^{2} / \mathrm{wk}$ and DID $>10 \mathrm{mg} / \mathrm{m}^{2} / \mathrm{wk}$ ) 
Table 4. Cox regression analysis for overall survival in elderly patients

\begin{tabular}{|c|c|c|c|c|c|c|}
\hline \multirow{2}{*}{ Variable } & \multicolumn{3}{|c|}{ Multivariate } & \multicolumn{3}{|c|}{ Univariate } \\
\hline & HR & $95 \% \mathrm{CI}$ & p-value & HR & $95 \% \mathrm{CI}$ & p-value \\
\hline B Symptom (yes vs. no) & 0.709 & $0.311-1.615$ & 0.413 & 0.403 & $0.218-0.746$ & 0.004 \\
\hline Ann Arbor stage (I/II vs. III/IV) & 0.601 & $0.204-1.765$ & 0.354 & 1.423 & $1.008-1.861$ & 0.010 \\
\hline Performance status (ECOG 0-1 vs. $\geq 2$ ) & 0.454 & $0.223-0.922$ & 0.029 & 2.867 & $1.586-5.182$ & $<0.001$ \\
\hline LDH level (normal vs. elevated) & 0.616 & $0.254-1.492$ & 0.283 & 2.390 & $1.212-4.711$ & 0.012 \\
\hline No. of extranodal sites (0-1 vs. $\geq 2$ ) & 0.864 & $0.426-1.730$ & 0.684 & 1.825 & $1.007-3.308$ & 0.047 \\
\hline IPI score (0-2 vs. $3-5)$ & 0.596 & $0.156-2.227$ & 0.449 & 3.137 & $1.715-5.738$ & $<0.001$ \\
\hline Bone marrow involvement (yes vs. no) & 1.922 & $0.848-4.353$ & 0.117 & 1.236 & $0.632-2.418$ & 0.536 \\
\hline Bulky tumor (yes vs. no) & 1.970 & $0.763-5.089$ & 0.161 & 0.782 & $0.363-1.684$ & 0.529 \\
\hline $\operatorname{DID}\left(<10 \mathrm{mg} / \mathrm{m}^{2} /\right.$ wk vs. $\left.\geq 10 \mathrm{mg} / \mathrm{m}^{2} / \mathrm{wk}\right)$ & 1.597 & $0.607-4.202$ & 0.343 & 0.446 & $0.206-0.965$ & 0.040 \\
\hline
\end{tabular}

HR, hazard ratio; CI, confidence interval; ECOG, Eastern Cooperative Oncology Group; LDH, lactate dehydrogenase; IPI, International Prognostic Index; DID, dose intensity of doxorubicin.

Table 5. Cause of death in elderly DLBCL patients (age $\geq$ 70 years)

\begin{tabular}{lcc} 
Cause & $\begin{array}{c}\text { DID } \leq 10 \\
\mathbf{m g} / \mathbf{m}^{2} / \mathbf{w k}\end{array}$ & $\begin{array}{c}\mathrm{DID}>\mathbf{1 0} \\
\mathbf{m g} / \mathbf{m}^{2} / \mathbf{w k}\end{array}$ \\
Treatment related mortality & $4(50.0)$ & $11(28.9)$ \\
Disease progression & $3(37.5)$ & $14(36.8)$ \\
Unknown & $1(12.5)$ & $9(23.7)$ \\
Secondary malignancy & 0 & $4(10.5)$ \\
\hline
\end{tabular}

Values are presented as number (\%). DLBCL, diffuse large B cell lymphoma; DID, dose intensity of doxorubicin.

in the young and elderly patients groups. The difference of survival was more significant in younger patients (Figs. 3 and 4). Survival outcomes in elderly DLBCL patients remained with no significant difference when DID was over $10 \mathrm{mg} / \mathrm{m}^{2} / \mathrm{wk}$.

\section{Prognostic factors and cause of death in elderly}

We utilized univariate and multivariate analyses to determine the effect of prognostic factors (B symptom, Ann Arbor stage, performance status, lactate dehydrogenase [LDH] level, number of extranodal sites, IPI score, bone marrow involvement, bulky tumor, and DID) on treatment outcome. Performance status, B symptom, IPI score, LDH level, and Ann Arbor stage, DID were identified as significant prognostic factors in univariate analysis. Performance status was the only prognostic factor associated with poor survival rate in multivariate analysis (Table 4).

Causes of death in elderly patients are shown in Table 5. Disease progression and treatment related mortality such as sepsis and bleeding were the major causes of death in elderly DLBCL patients, regardless of DID.

\section{Discussion}

Significantly shorter survival was observed for DID $\leq 10$ $\mathrm{mg} / \mathrm{m}^{2} / \mathrm{wk}$ than for DID $>10 \mathrm{mg} / \mathrm{m}^{2} /$ wk in elderly patients with DLBCL. When more than $10 \mathrm{mg} / \mathrm{m}^{2} /$ wk of doxorubicin was administered, no significant differences were observed in treatment outcomes according to DID (2-year OS rate, $75.0 \% ; 10.0 \mathrm{mg} / \mathrm{m}^{2} / \mathrm{wk}<\mathrm{DID} \leq 11.7 \mathrm{mg} / \mathrm{m}^{2} / \mathrm{wk}[60 \%-70 \%$ of standard DID], $66.7 \% ; 15.0 \mathrm{mg} / \mathrm{m}^{2} / \mathrm{wk}<$ DID $\leq 16.7$ $\mathrm{mg} / \mathrm{m}^{2} / \mathrm{wk}[90 \%-100 \%$ of standard DID]; $\mathrm{p}=0.815$ ). Each subgroup divided by $1.7 \mathrm{mg} / \mathrm{m}^{2} / \mathrm{wk}$ of DID showed insignificant difference in PFS and OS. CR rate and disease progression rate were similar regardless of DID; however, survival outcomes improved with more than $10 \mathrm{mg} / \mathrm{m}^{2} / \mathrm{wk}$ of doxorubicin in patients aged $\geq 70$ years. Patients younger than 70 showed significant difference in $C R$ rate, disease progression rate, and treatment outcomes by DID.

DID was not associated with treatment related mortality. The reason for this finding was assumed to be the small number of expired patients $(n=46)$. The cause of death was unknown in 21.3\%. Performance status was an independent prognostic factor in multivariative analysis, and the elderly patients had a poorer performance status than young patients, which was in agreement with past studies $[15,16]$.

A previous study which analyzed treatment outcomes according to DID before the rituximab era reported that patients with DID $\geq 10 \mathrm{mg} / \mathrm{m}^{2} /$ wk had better treatment outcomes than DID $<10 \mathrm{mg} / \mathrm{m}^{2} / \mathrm{wk}$ in elderly patients with 
DLBCL [7]. A recent study showed that low-dose CHOP (mini-CHOP) plus rituximab was effective and safe in DLBCL patients aged $\geq 80$ years [17]. Our study showed that DID can be reduced; however, maintenance of DID $\geq 10$ $\mathrm{mg} / \mathrm{m}^{2} / \mathrm{wk}$ was necessary in elderly DLBCL patients in the rituximab era.

Doxorubicin is essential to CHOP or R-CHOP. However, elderly patients could not receive full dose doxorubicin due to myocardial toxicity. A recent study showed that elderly DLBCL with CHOP or R-CHOP had an increased risk of cardiovascular disease, such as congestive heart failure, cardiomyopathy and acute myocardial infarction [18]. Several studies were conducted with additional alternate anti-cancer drugs such as bleomycin, and pixantrone, to reduce the myocardial damage of doxorubicin-based chemotherapy in elderly patients. However, they were less effective or no more beneficial than CHOP [19-22]. It is thus important to determine the tolerable dose of doxorubicin that achieves comparable treatment outcomes.

Our study had some limitations. First, it was a retrospective, single center study on a small patient population. Additional studies are required to differentiate between elderly and young patients. Second, there is no consensus on the definition of 'elderly' among DLBCL patients. According to the IPI, age $\geq 60$ years was a poor prognostic factor [23]. Several studies evaluating the effect of age on prognosis showed that $>70$ years was a significant adverse factor [24]. We analyzed treatment outcomes according to the 70 year definition. As life expectancy increases, a consensus on the definition of 'elderly' is necessary and follow-up study is needed. How- ever the strength of our study lay in the comparison of treatment outcomes according to DID in several subgroups.

\section{Conclusion}

DID was required at a minimum of $10 \mathrm{mg} / \mathrm{m}^{2}$ per week in elderly patients with DLBCL in the rituximab era. Despite improved survival outcomes by the introduction of rituximab, maintenance of DID was still important to the treatment of elderly DLBCL patients.

\section{Conflicts of Interest}

Conflict of interest relevant to this article was not reported.

\section{Acknowledgments}

This study was supported by grants from the Innovative Research Institute for Cell Therapy, Republic of Korea (A062260).

\section{References}

1. Morton LM, Wang SS, Devesa SS, Hartge P, Weisenburger DD, Linet MS. Lymphoma incidence patterns by WHO subtype in the United States, 1992-2001. Blood. 2006;107:265-76.

2. Armitage JO. Treatment of non-Hodgkin's lymphoma. N Engl J Med. 1993;328:1023-30.

3. Coiffier B, Thieblemont C, Van Den Neste E, Lepeu G, Plantier I, Castaigne S, et al. Long-term outcome of patients in the LNH-98.5 trial, the first randomized study comparing rituximab-CHOP to standard CHOP chemotherapy in DLBCL patients: a study by the Groupe d'Etudes des Lymphomes de l'Adulte. Blood. 2010;116:2040-5.

4. Tirelli U, Errante D, Van Glabbeke M, Teodorovic I, KluinNelemans JC, Thomas J, et al. CHOP is the standard regimen in patients $>$ or $=70$ years of age with intermediate-grade and high-grade non-Hodgkin's lymphoma: results of a randomized study of the European Organization for Research and Treatment of Cancer Lymphoma Cooperative Study Group. J Clin Oncol. 1998;16:27-34.
5. Armitage JO. Is lymphoma occurring in the elderly the same disease? Leuk Lymphoma. 2008;49:14-6.

6. Huntington SF, Talbott MS, Greer JP, Morgan DS, Reddy N. Toxicities and outcomes among septuagenarians and octogenarians with diffuse large B-cell lymphoma treated with rituximab, cyclophosphamide, doxorubicin, vincristine and prednisone therapy. Leuk Lymphoma. 2012;53:1461-8.

7. Lee KW, Kim DY, Yun T, Kim DW, Kim TY, Yoon SS, et al. Doxorubicin-based chemotherapy for diffuse large B-cell lymphoma in elderly patients: comparison of treatment outcomes between young and elderly patients and the significance of doxorubicin dosage. Cancer. 2003;98:2651-6.

8. Coiffier B, Lepage E, Briere J, Herbrecht R, Tilly H, Bouabdallah $\mathrm{R}$, et al. CHOP chemotherapy plus rituximab compared with CHOP alone in elderly patients with diffuse large-B-cell lymphoma. N Engl J Med. 2002;346:235-42.

9. Shin HJ, Chung JS, Song MK, Kim SK, Choe S, Cho GJ. Addition of rituximab to reduced-dose CHOP chemotherapy is fea- 
sible for elderly patients with diffuse large B-cell lymphoma. Cancer Chemother Pharmacol. 2012;69:1165-72.

10. Feugier P, Van Hoof A, Sebban C, Solal-Celigny P, Bouabdallah R, Ferme C, et al. Long-term results of the R-CHOP study in the treatment of elderly patients with diffuse large B-cell lymphoma: a study by the Groupe d'Etude des Lymphomes de l'Adulte. J Clin Oncol. 2005;23:4117-26.

11. Bastion Y, Blay JY, Divine M, Brice P, Bordessoule D, Sebban $\mathrm{C}$, et al. Elderly patients with aggressive non-Hodgkin's lymphoma: disease presentation, response to treatment, and survival: a Groupe d'Etude des Lymphomes de l'Adulte study on 453 patients older than 69 years. J Clin Oncol. 1997;15: 2945-53.

12. Campo E, Swerdlow SH, Harris NL, Pileri S, Stein H, Jaffe ES. The 2008 WHO classification of lymphoid neoplasms and beyond: evolving concepts and practical applications. Blood. 2011;117:5019-32.

13. Cheson BD, Pfistner B, Juweid ME, Gascoyne RD, Specht L, Horning SJ, et al. Revised response criteria for malignant lymphoma. J Clin Oncol. 2007;25:579-86.

14. Hryniuk WM, Goodyear M. The calculation of received dose intensity. J Clin Oncol. 1990;8:1935-7.

15. Arcaini L, Rattotti S, Gotti M, Luminari S. Prognostic assessment in patients with indolent B-cell lymphomas. ScientificWorldJournal. 2012;2012:107892.

16. Sehn LH, Berry B, Chhanabhai M, Fitzgerald C, Gill K, Hoskins $\mathrm{P}$, et al. The revised International Prognostic Index (R-IPI) is a better predictor of outcome than the standard IPI for patients with diffuse large B-cell lymphoma treated with R-CHOP. Blood. 2007;109:1857-61.

17. Peyrade F, Jardin F, Thieblemont C, Thyss A, Emile JF, Castaigne $S$, et al. Attenuated immunochemotherapy regimen (R-miniCHOP) in elderly patients older than 80 years with dif- fuse large B-cell lymphoma: a multicentre, single-arm, phase 2 trial. Lancet Oncol. 2011;12:460-8.

18. Tsai HT, Pfeiffer RM, Warren J, Wilson W, Landgren O. The effects of cardiovascular disease on the clinical outcome of elderly patients with diffuse large B-cell lymphoma. Leuk Lymphoma. 2015;56:682-7.

19. Sonneveld P, de Ridder M, van der Lelie H, Nieuwenhuis K, Schouten H, Mulder A, et al. Comparison of doxorubicin and mitoxantrone in the treatment of elderly patients with advanced diffuse non-Hodgkin's lymphoma using CHOP versus CNOP chemotherapy. J Clin Oncol. 1995;13:2530-9.

20. Tilly H, Lepage E, Coiffier B, Blanc M, Herbrecht R, Bosly A, et al. A randomized comparison of ACVBP and CHOP in the treatment of advanced aggressive non-Hodgkin's lymphoma: the LNH93-5 study. Blood. 2000;96:832A.

21. Herbrecht R, Cernohous P, Engert A, Le Gouill S, Macdonald $\mathrm{D}$, Machida $\mathrm{C}$, et al. Comparison of pixantrone-based regimen (CPOP-R) with doxorubicin-based therapy (CHOP-R) for treatment of diffuse large B-cell lymphoma. Ann Oncol. 2013; 24:2618-23.

22. Kreher S, Lammer F, Augustin D, Pezzutto A, Baldus CD. R-split-CHOP chemotherapy for elderly patients with diffuse large B-cell lymphoma. Eur J Haematol. 2014;93:70-6.

23. A predictive model for aggressive non-Hodgkin's lymphoma. The International Non-Hodgkin's Lymphoma Prognostic Factors Project. N Engl J Med. 1993;329:987-94.

24. Advani RH, Chen H, Habermann TM, Morrison VA, Weller EA, Fisher RI, et al. Comparison of conventional prognostic indices in patients older than 60 years with diffuse large B-cell lymphoma treated with R-CHOP in the US Intergroup Study (ECOG 4494, CALGB 9793): consideration of age greater than 70 years in an elderly prognostic index (E-IPI). Br J Haematol. 2010;151:143-51. 